\title{
NOTAS PARA A HISTÓRIA DA EDUCAÇÃO: CONSIDERAÇÕES \\ ACERCA DO DECRETO N 7.247, DE 19 DE ABRIL DE 1879, DE AUTORIA DE CARLOS LEÔNCIO DE CARVALHO
}

\author{
APRESENTAÇÃO
}

\author{
Cristiane Silva Melo \\ Faculdade Estadual de Ciências e Letras de Campo Mourão - FECILCAM \\ Maria Cristina Gomes Machado \\ Universidade Estadual de Maringá - UEM
}

\section{Introdução}

O Documento que ora apresentamos tem sido referência em pesquisas que se dedicam ao entendimento das mudanças ocorridas no campo educacional no Brasil na segunda metade do século XIX. O Decreto número 7.247, instituído por Carlos Leôncio de Carvalho em 19 de abril de 1879 (CARVALHO, 1942), provocou uma série de discussões sobre a organização do sistema de ensino brasileiro. Discutimos, neste texto, determinados aspectos, especificidades e conteúdos do referido documento que ao ser definido, propôs reformas no ensino primário e secundário do Município da Corte, cidade de Rio de Janeiro, e no ensino superior em todo o Império.

O Decreto 7.247 consiste num interessante documento que expressa aspirações de modificar a estrutura do ensino num contexto de efervescência social. Nesse período, em diversos setores, foram pensadas direções a serem seguidas com vistas ao desenvolvimento da sociedade brasileira, a educação foi percebida como um elemento importante para esse processo.

Cumpre destacar que a sociedade brasileira, na segunda metade do século XIX, vivenciou intensas mudanças nos âmbitos político, econômico, cultural e social. Nesse momento, tornou-se ainda mais expressiva a ideia de modernização da sociedade, houve um incentivo à industrialização e um notável desenvolvimento das atividades industriais, sendo verificado um aumento na importação do carvão e de maquinários para o país (RIBEIRO, 1993). Dentre diversas ocorrências, é importante frisar a progressão, na década de 1870 , da política imigratória ${ }^{1}$ e o desenvolvimento, na década de 1880 , de novas relações de trabalho com a abolição da escravidão - 1888 -, assim como a inserção de novas estratégias políticas e econômicas com o advento da República - 1889. Sobre o final do século XIX, um importante estudioso da educação brasileira assegura:

Em nenhuma época do século XIX, depois da Independência, se prepararam e se produziram acontecimentos tão importantes para a vida nacional como no último quartel desse século em que se verificou o primeiro surto industrial, se estabeleceu uma política imigratória, se aboliu o regime da escravidão, se iniciou a organização do trabalho livre e se inaugurou, com a queda do Império, a experiência de um novo regime político. (AZEVEDO, 1963, p. 607).

A modernização da sociedade brasileira era uma exigência do processo de alterações que se processava na sociedade, que, de economia fundamentalmente rural, iniciava um processo de industrialização e urbanização. Acontecimentos e mudanças sociais 
acompanharam o ideário e efetivação de modernização das relações capitalistas de produção. Tais acontecimentos podem ser enumerados: a abolição da escravatura, a imigração estrangeira, o trabalho assalariado, a colonização das terras, o aumento do meio circulante, a organização de um sistema de créditos à grande lavoura, o casamento civil, a liberdade religiosa, entre outros.

Nesse contexto de transformações, ideários liberais e positivistas ganharam ênfase nas décadas finais do século XIX, sendo considerados em ações governamentais e em leis na definição de orientações voltadas às reformas e mudanças na sociedade, com vistas à sua modernização e progresso. Os princípios liberais influenciaram debates relacionados à educação, apresentando-se, em muitas das discussões sobre reformas no ensino, como o ideário de "liberdade de ensino", defendido por muitos políticos liberais. O ensino livre era uma aspiração dos que eram a favor dos princípios liberais na política e na administração do país.

A educação, nas décadas finais do período imperial, foi posta em debate por ser considerada um fator importante no desenvolvimento da sociedade brasileira. Diversos intelectuais a definiram como um meio indispensável à preparação do trabalhador e cidadão nacional, vislumbrava-se a possibilidade de a educação contribuir para o progresso. Carlos Leôncio de Carvalho foi um dos autores que destacou a educação como um elemento significativo na formação e vida do homem, bem como indispensável para a sociedade. Em Relatório apresentado à Assembléia Legislativa no ano de 1878, Leôncio de Carvalho apontou:

A instrução constitui elemento vital das sociedades modernas; ela é a primeira condição de qualquer progresso material e moral, porque ela é sua luz como a liberdade é sua atmosfera. Todas as instituições dela dependem, pelo jogo regular de seu mecanismo, sobretudo aquelas que estão ligadas de um modo imediato e essencial à vida política e social das nações; porque, à medida que cresce seu fundo científico, os povos descobrem novos horizontes e marcham mais seguramente em busca de seu ideal de perfectibilidade, reformando o presente, preparando o futuro e melhorando cada vez mais as condições de sua existência. (CARVALHO, apud ALMEIDA, 1989, p. 182).

No campo educacional, apresentavam-se inúmeros problemas, assim, foram diversos os relatórios sobre a instrução pública apresentados para discussão e os projetos de reformas propostos com vistas a mudanças na organização do ensino. Fazemos memória do projeto de Paulino José Soares de Souza -1870-, o de Antonio Candido Cunha Leitão 1873-, o de João Alfredo Corrêa de Oliveira -1874-, o Decreto n. 7.247 de Leôncio de Carvalho -1879-, os pareceres-projetos de Rui Barbosa -1882/1883-, o de Almeida de Oliveira -1882- e o de Barão de Mamoré -1886 (MACHADO, 2002).

Essa quantidade de projetos propostos entre o período de 1870 a 1886 , sete em menos de duas décadas, expressa a importância que os políticos atribuíam à educação, concebendo-a como fundamental para a sociedade brasileira, em época de definição e de intensas mudanças que ocorreriam nas instâncias sociais. A "gratuidade do ensino", já expressa na Constituição outorgada em 1824, foi um dos temas defendidos pela maioria dos projetos, sendo destacado como necessárias a fundação e equiparação de instituições educativas que possibilitassem à população o acesso à educação. Pela importância histórica desse debate, nós o destacamos no supracitado Decreto, apresentado nesse número da revista. 


\section{O Decreto 7.247 de Carlos Leôncio de Carvalho}

Em 1879, Carlos Leôncio de Carvalho², que no momento ocupava o cargo de Ministro dos Negócios do Império, pasta na qual se encontrava submetida a instrução pública do país, por meio de um Decreto, instituiu uma reforma do ensino com a proposta de mudanças na área de ensino primário e secundário do município da Corte e no ensino superior em todo o império. Sobre o autor, convém frisarmos a importância de sua atuação nas discussões, debates e propostas em torno da definição de um sistema de educação nacional na segunda metade do século XIX. Carvalho exerceu atividades docentes e administrativas em instituições de ensino, atuando como professor e diretor na Faculdade de Direito de São Paulo, em São Paulo, e lente e diretor na Faculdade Livre de Direito, no Rio de Janeiro. Participou ativamente da vida pública nacional, assumiu atividade na pasta dos Negócios do Império, sendo nomeado por Cansanção de Sinimbu. Foi eleito Deputado pela província de São Paulo e senador estadual no governo de Américo Brasiliense. Seu conjunto de obras é composto de textos, documentos de caráter legal, relatórios, pareceres, artigos, entre outros ${ }^{3}$.

No final do século XIX, foi enfática a discussão sobre a realização de reformas em todos os graus da instrução pública. A Reforma de Leôncio de Carvalho apresentou determinadas inovações em relação a reformas anteriores, com relação à Reforma de Couto Ferraz, Decreto n. 1.331-A, de 17 de fevereiro de 1854, que aprovou o "Regulamento para a reforma do ensino primário e secundário do Município da Corte", destacam-se as novas ideias:

[...] criação de jardins-de-infância para as crianças de 3 a 7 anos (artigo $5^{\circ}$ ); caixa escolar (artigo $6^{\circ}$ ); bibliotecas e museus escolares (artigo $7^{\circ}$ ); subvenção ao ensino particular, equiparação de Escolas Normais particulares às oficiais e de escolas secundárias privadas ao Colégio Pedro II, criação de escolas profissionais de bibliotecas populares e de bibliotecas e museus pedagógicos onde houver Escola Normal (artigo $8^{\circ}$ ); regulamentação do ensino superior abrangendo a associação de particulares para a fundação de cursos livres em salas dos edifícios das Escolas ou Faculdades do Estado (artigo 22); faculdade de direito (artigo 23; e faculdades de medicina (artigo 24). [...] a Reforma Leôncio de Carvalho levou bem mais longe a inclusão de dispositivos referentes ao funcionamento da educação nas províncias. Assim, o artigo $8^{\circ}$ contempla, nas províncias, a subvenção a escolas particulares; a contratação de professores particulares para ministrar os rudimentos do ensino primário; a criação de cursos de alfabetização de adultos e de Escolas Normais; fundação de bibliotecas e museus pedagógicos e de bibliotecas populares; e a criação, nos municípios mais importantes das províncias, de escolas profissionais e de ensino de artes e ofícios. A Reforma previu, também, a abertura, nas províncias, de mesas de exames de preparatórios (artigos 11 e 12) e a inspeção dos estabelecimentos de instrução primária e secundária (artigo 15). (SAVIANI, 2007, p. 138)

Registros sobre a situação do ensino público revelavam a necessidade de ação por parte do Estado na solução de problemas encontrados no campo educacional. Uma das questões, apontadas como problemática em documentos oficiais, foi a insuficiência da quantidade de instituições educativas a oferecerem educação à população. Segundo dados, 
o ensino não alcançava satisfatoriamente as camadas populares, sendo alto os índices de analfabetismo no país.

Os dados sobre a instrução nesse período indicam a urgência da intervenção, bem como as dificuldades que se apresentam a tal empreendimento. Em 1877 os relatórios oficiais apontam que, de uma população livre de 6.858 .594 habitantes, sabem ler e escrever apenas 1.563.078. O número de escolas primárias era $70 \%$ inferior ao minimamente desejável. O ensino secundário restringia-se a aulas avulsas com exceção de poucos colégios, e de poucos cursos superiores que, mal aparelhados, atendiam à pequena parcela da população que buscava o titulo de bacharel, menos pela profissionalização e mais pela reafirmação dos privilégios por ele possibilitados. (VALDEMARIN, 2000, p. 62).

Nesse contexto, a ideia sobre a educação como um fator indispensável à formação do cidadão nacional, bem como ao desenvolvimento e modernização da sociedade se intensificou, ao lado da defesa da ampliação das condições de acesso à educação e à qualidade do ensino. O supracitado Decreto, na década de 1870, expressava a importância atribuída ao ideário de expansão do ensino em todos os níveis ao destacar a liberdade de ensino em seu artigo primeiro. Desta forma, permitia, em termos legais, a fundação e equiparação de instituições educativas, ou seja, previa o consequente crescimento da quantidade de cursos primários e secundários no município da corte, assim como de cursos no ensino superior em todo país.

O Decreto 7.247 continha vinte e nove artigos, dentre suas determinações, definia a instrução primária como um ensino obrigatório; instituía a liberdade de ensino e de consciência; destacava a ideia de incompatibilidade do professorado com a realização de atividades em outros cargos públicos e administrativos; estabelecia a não obrigatoriedade do ensino religioso no ensino, nesse caso, a instrução religiosa não era obrigatória aos nãocatólicos, podendo ser oferecida em determinados dias, antes ou depois das aulas das séries no ensino regular; autorizava, na área da instrução superior, a promoção e fundação de cursos particulares; suspendia o regime de faltas, lições e sabatinas no ensino secundário e superior; apontava a liberdade de frequência e a não obrigação da prestação de exame eclesiástico aos não-católicos; previa para a instrução secundária a livre frequência no externato; definia disciplinas e conteúdos em programas de ensino de cursos profissionalizante, como o curso de formação de professores, o ensino nas escolas normais e nos programas do ensino superior, como os cursos de Medicina e de Direito; buscava a organização do ensino primário, relacionando as escolas do primeiro ao segundo grau, como no sistema americano, e introduzia as "lições de coisas" como disciplina.

O Decreto previa a criação de jardins de infância em cada distrito do município da Corte voltados à educação de crianças de três a sete anos de idade, a co-educação dos sexos nas escolas, a existência de escolas mistas, as caixas escolares, a organização de bibliotecas e museus, de escolas para a instrução elementar (ler, escrever e contar), o oferecimento de cursos para adultos analfabetos, a construção de prédios apropriados às escolas públicas, a ampliação da quantidade de escolas normais, a realização de conferências pedagógicas e a organização do Conselho Diretor da Instrução Pública no Município da Corte. Dentre essas medidas, nenhuma causou mais polêmica do que a liberdade de ensino e de frequência. 


\subsection{A liberdade de ensino e de frequiência}

O Decreto 7.247 determinava ser livre o ensino primário e secundário no município da corte e o superior em todo o Império, prevendo como necessária a inspeção para a garantia das condições denominadas "moralidade" e "higiene". Para isso, era preciso que os professores que mantivessem aulas ou cursos e diretores dos estabelecimentos de instrução primária ou secundária a serem fundados comunicassem ao inspetor geral da instrução pública, dentre o prazo de um mês, a abertura e o local de funcionamento dos cursos e escolas, assim como as informações sobre o público a ser atendido, as condições de admissão, o programa do ensino e sobre os professores a ministrarem tais aulas e cursos. Era tarefa dos responsáveis pelos cursos e instituições de ensino apresentar todas as informações solicitadas pelas autoridades competentes. As faculdades "livres", pelo Decreto 7.247, possuíam o direito de conferir a seus alunos os graus acadêmicos que as escolas ou faculdades do Estado pudessem conceder desde que os alunos obtivessem as devidas aprovações em acordo com os estatutos para a colação do mesmo grau.

A liberdade de ensino definida pelo Decreto pode ser percebida, ainda, como a possibilidade de todos que se sentissem preparados esporem suas ideias em acordo com o método que concebessem como o mais adequado. Sobre a acepção da liberdade de ensino no Decreto 7.247, recorremos às afirmações de Valdemarin (2000, p. 64), que apresenta as seguintes considerações:

O maior mérito do Decreto $n^{\circ} 7.247$ é explicitar uma das interpretações possíveis da expressão liberdade de ensino. Entendida ora como liberdade de abrir escolas, ora como liberdade de pensamento e expressão, ora, ainda, como não interferência do Estado, a liberdade de ensino se apresenta ao debate como uma questão importante, dada sua centralidade ao liberalismo, esbarrando, contudo, nessa imprecisão. Ao definir no Decreto uma das interpretações possíveis, registra-se documentalmente uma das vertentes, possibilitando a análise de seus fundamentos e tornando mais concreto o debate da questão.

Carvalho entendia que a prosperidade dos Estados Unidos e de países europeus devia-se, também, ao princípio de liberdade de ensino. Ele era enfático ao defender a adoção da liberdade de ensino, já que a considerava importante para o desenvolvimento da educação nacional, por acreditar que tal princípio traria benefícios à sociedade brasileira. Vejamos suas declarações:

Em matéria de instrução, se foi feita alguma coisa entre nós, há muito mais ainda a se fazer para dar o impulso indispensável, para que o país possa colher todos os frutos que tem condições de produzir. A primeira medida a realizar, para obter este desiderato, é a liberdade de ensino, que é a base sólida sobre a qual devemos assentar o edifício da educação nacional. [...] Em toda classe de professores, sempre se preferirá aqueles que ensinarão mais e melhor e, da emulação que se desenvolverá entre eles, por causa da livre concorrência, ter-se-á uma feliz influência nos alunos e, por conseguinte, na sociedade inteira. O Estado ganhará com isso, porque terá, sob suas mãos um pessoal hábil, do qual poderá escolher professores oficiais; estes, por sua vez, para não verem suas escolas desertas e sua reputação comprometida, serão obrigados a estudar mais, a serem zelosos para realizar bem sua augusta missão. (CARVALHO, apud ALMEIDA, 1989, p. 183). 
A situação de problemas existentes na área de ensino, no final do Império no Brasil, foi explicada por diversos políticos e educadores, naquele momento, como resultante da "falta de liberdade" que as instituições particulares possuíam de fundar e manter escolas (HOLANDA, 1985, p. 377).

O Decreto 7.247 previa a liberdade de frequência, bem como a liberdade de escolha pelos alunos dos cursos secundários e superior em optar por estudos que preferissem e nos locais que almejassem. As instituições escolares deveriam ser rígidas não no controle da frequência, mas no controle dos exames, o que implicava numa outra organização de Cursos, por matéria e não por anos, os alunos escolheriam as matérias e o tempo para cumprir as determinadas séries. Tal intenção denota contradições, o princípio da liberdade na frequência deparava-se com a existência do regime de escravidão no país, o qual foi abolido em 1881, os indivíduos livres poderiam até possuir a liberdade de escolha, mas não os escravos, que estavam subordinados à vontade de outros. Notícias explanavam a falta de rigor na realização de exames nas províncias, fator que não possibilitaria bons resultados pela frequência livre, e o máximo rigor nos exames não foi procedimento inaugurado com o Decreto.

A "livre frequência", prevista no Decreto 7.247, consistiu num assunto bastante polêmico. A intenção já havia sido combatida em outros momentos por alguns exministros do Império, Visconde de Ouro Preto posicionou-se contra ao regime de livre frequiência, interpretando-o como não condizente aos meios de ensino vigentes no país. $\mathrm{O}$ Conselho de Estado, ao se pronunciar, opinou pela não validade da parte sobre a livre frequiência do Decreto. Não menos polêmico, entretanto, foram as discussões em torno do tema da obrigatoriedade e gratuidade do ensino.

\subsection{A obrigatoriedade e a gratuidade do ensino}

O Decreto 7.247 estabeleceu que os indivíduos de sete a quatorze anos, no município da Corte, estariam obrigados a frequentarem as escolas primárias do primeiro grau, salvo os que os pais ou responsáveis provassem que tais crianças e jovens receberiam instrução em escolas particulares ou em suas próprias casas e, ainda, aos que morassem numa distância de um e meio quilômetro para os meninos e de um quilômetro para as meninas da escola pública. Os responsáveis que não seguissem a determinação de oferta de educação primária aos indivíduos em condições de recebê-la estariam sujeitos ao pagamento de multa. Multas também deveriam ser pagas pelos responsáveis que, ao serem advertidos da pouca frequência da criança na escola, não apresentassem justificativas coerentes ou não provassem a regularidade do ensino particular em que a criança estava submetida.

A obrigatoriedade do ensino primário previa o auxílio do Estado para garantir as condições de oferta da educação. Os indivíduos em idade escolar de sete a quatorze anos e economicamente pobres, cujos responsáveis justificassem a impossibilidade de prepará-los para frequentarem a escola, poderiam receber vestuário escolar, livros e materiais indispensáveis ao estudo. A obrigatoriedade de ensino primário exigia, por um lado, a ampliação da quantidade de instituições educativas para atender a toda população em idade de recebê-lo e, por outro, este era um investimento considerado necessário, visto possuir possibilidades de trazer benefícios à sociedade. Por meio da educação, poder-se-ia moralizar o povo, incutindo-lhe hábitos de higiene e amor ao trabalho, de modo a desenvolver a indústria e aumentar a riqueza pública.

A educação do povo foi destacada como condição para o progresso. O ensino, concebido como indispensável à formação integral do homem, era posto como um dos 
elementos importantes a ser pensado e organizado, deveria, portanto, sofrer intervenções para o seu desenvolvimento.

A questão da religião, o ensino das "lições de coisas" e os programas de ensino provocaram debate na sociedade.

\subsection{O programa de ensino de instituições escolares, a instrução religiosa e o ensino das "lições de coisas".}

O Decreto 7.247 fixava matérias a conterem no ensino das escolas primárias do primeiro grau, das escolas do segundo grau, das escolas normais e das faculdades de Direito e de Medicina.

O ensino nas escolas primárias do primeiro grau do município da Corte constaria das disciplinas de "Instrução moral; Instrução religiosa; Leitura; Escrita; Noções de Cousas; Noções essenciais de gramática; Princípios elementares de aritmética; Sistema legal de pesos e medidas; Noções de história e geografia do Brasil; Elementos de desenho linear; Rudimentos de música, com exercício de solfejo e canto e Ginástica e Costura simples (para as meninas)". O ensino nas escolas do segundo grau consideraria a continuação e o desenvolvimento das disciplinas ensinadas no primeiro grau e das disciplinas de "Princípios elementares de álgebra e geometria; Noções de física, química e história natural, com explicação de suas principais aplicações à indústria e aos usos da vida; Noções gerais dos deveres do homem e do cidadão, com explicação sucinta da organização política do Império; Noções de lavoura e horticultura; Noções de economia social (para os meninos); Noções de economia doméstica (para as meninas); Prática manual de ofícios (para os meninos) e Trabalhos de agulhas (para as meninas)" (CARVALHO, 1942, p. 276277).

O Decreto previa a divisão nas faculdades de Direito em duas sessões, a das ciências jurídicas e a das sociais, e, nos cursos da faculdade de Medicina, a divisão em cursos ordinários e complementares. Tais sessões e cursos compreenderiam matérias específicas. Definia que, em cada uma das faculdades de Medicina, estaria uma escola de farmácia, um curso de obstetrícia e ginecologia e de cirurgia dentária.

A ausência de obrigatoriedade dos alunos não-católicos à frequência em aulas de instrução religiosa era assegurada pelo Decreto 7.247. Este ainda deliberava que o juramento de graus acadêmicos, dos diretores, lentes, funcionários de escolas e faculdades, assim como de professores do ensino primário e secundário seria prestado conforme a religião de cada um, ou substituído pela promessa de "bem cumprimento dos deveres" referentes aos graus ou funções assumidas.

A definição da disciplina "Noções de coisas", no currículo escolar das escolas primárias do primeiro grau, consistiu num assunto interessante. Esta foi prevista, pelo Decreto, para a aprendizagem dos estudantes do ensino normal. $\mathrm{O}$ ensino nas escolas normais do Estado compreenderia a disciplina "Prática do ensino intuitivo ou lições de cousas" (CARVALHO, 1942, p. 280). Para Schelbauer (2005), o método intuitivo, conhecido como lições de coisas ${ }^{4}$, foi considerado o mais adequado à instrução das classes populares na segunda metade do século XIX, sendo, na realidade brasileira, propagado por muitos intelectuais, proprietários de escolas, diretores e professores, homens públicos, juristas e reformadores.

Em 1886, houve a publicação, na cidade de Rio de Janeiro, da obra Primeiras Lições de Coisas, versão de Rui Barbosa (1956) sobre a obra do americano Alison Calkins, intitulada Primary Object Lesson. O autor adaptou à linguagem nacional as ideias de Calkins, objetivando difundir princípios do método intuitivo que acreditava como eficaz na 
formação integral dos indivíduos. Nos anos finais do Império, Primeiras Lições de Coisas consistiu num manual de ensino elementar destinado ao uso de professores e pais na educação das crianças. Foi uma obra aprovada pelo Conselho Superior da Instrução Pública da Bahia e pelo Conselho Diretor da Corte adotada pelo Governo Imperial para ser útil aos educadores nas escolas primárias.

O método intuitivo, conforme exposto por Schelbauer (2005), consistiu num dos principais elementos da renovação educacional proposta por intelectuais no país, sendo abordado em projetos de reforma, em pareceres e em conferências pedagógicas, assim como em práticas educacionais relacionadas a iniciativas governamentais e particulares, as quais acreditavam nas possibilidades da educação contribuir para modificações da realidade da nação.

\section{Considerações finais}

Leôncio de Carvalho decretou a Reforma do ensino sem a prévia discussão e deliberações da Câmara dos Deputados. Os trâmites procedimentais consistiam na apresentação do projeto de reforma à Câmara dos Deputados para discussão e aprovação. Assim, entraram em vigor de imediato as disposições que não "necessitavam" de aprovação da Assembleia, outras foram direcionadas para verificação e aprovação e passaram a aguardar o parecer da Comissão de Instrução (CALVI, 2003). A tarefa de apreciação do Decreto 7.247 foi atribuída à Comissão de Instrução Pública, composta por Rui Barbosa, que havia substituído Flanklin Dória, por Thomaz do Bonfim Spinola e por Ulisses Viana.

Rui Barbosa foi o relator, escreveu pareceres-projetos sobre o ensino primário, secundário e superior a partir da análise do Decreto 7.247. O parecer "A Reforma do ensino secundário e Superior" (BARBOSA, 1942) é datado de 13 de abril de 1882 e o parecer "Reforma do ensino primário e várias instituições complementares da instrução pública" (BARBOSA, 1947) de 12 de setembro de 1882, estes apenas apareceram nos anais do Parlamento no ano de 1883 (MACHADO, 2005).

Os pareceres de Rui Barbosa podem ser considerados, segundo Holanda (1985, p. 378), “[...] um projeto de reforma global da educação brasileira", para a definição, naquele momento, de um plano nacional de educação, os documentos contemplaram variados aspectos da educação, abrangendo noções de filosofia, de política, de administração, de didática e psicologia, e, ainda, forneceu dados relativos a uma análise de educação comparada. Consistem, a exemplo do Decreto 7.247, em importantes materiais que contribuem para a elucidação dos debates sobre a instrução pública ocorridos na segunda metade do século XIX.

Os pareceres de Rui Barbosa, por apresentarem uma ampla discussão sobre as instituições escolares, revelam-se fundamentais para o historiador da educação que investiga suas origens no Brasil. Este autor compilou dados sobre a organização do sistema escolar em diversos países e, ao mesmo tempo, descreveu meticulosamente a situação do ensino brasileiro em três níveis de ensino: no ensino primário, no ensino secundário e no ensino superior. Apresentou propostas para a reformulação destes níveis em consonância com as novas necessidades sociais, acrescentando a necessidade de oferta do ensino para as crianças menores de 7 anos nos jardins-de-infância. (MACHADO, 2004, p. 81-82) 
Leôncio de Carvalho deixou a pasta de Ministro do Império em junho de 1879, sua Reforma provocou algumas implicações à instrução pública. Registros sobre a aplicação do Decreto $n^{\circ} 7.247$ na educação brasileira podem ser verificados na obra de Primitivo Moacyr "A Instrução e o Império".

Sabe-se que a Assembléia Legislativa acabou por não referendar o Decreto na íntegra, algumas disposições resultavam em aumento de despesas, outras necessitavam de maiores estudos para aprovação (CUNHA, 1986) Dentre as determinações do Decreto que passaram a vigorar, destaca-se a garantia da liberdade de crenças de alunos e professores das escolas públicas de todos os níveis, os alunos não-católicos ficaram isentos do estudo da religião e do juramento católico para a obtenção de graus acadêmicos (HAIDAR, 1972). No que concerne ao ensino superior, é interessante destacar que resistências se apresentaram sobre a ideia de participação do setor privado nesse grau de ensino. Alguns comentavam ser inócua tal medida, a liberdade de ensino superior existira desde o início do Império, e foi percebido, na época do estabelecimento do Decreto, pouco aproveitamento da instrução superior pela iniciativa privada. Outros ainda afirmavam que a diminuição do controle do Estado na área de ensino superior prejudicaria a qualidade do referido ensino. É provável que tais resistências expressassem a defesa do monopólio de concessão de diplomas juridicamente válidos no país.

A Reforma de Leôncio de Carvalho foi aprovada e estabelecida, ao contrário de outros projetos como os de Paulino José Soares de Souza, 1870; Antônio Cândido da Cunha Leitão, 1873, e de João Alfredo Correa de Oliveira, 1874, apresentados após a Reforma de Couto Ferraz em 1854. Os pareceres-projetos de Rui Barbosa, propostos após a análise do Decreto 7.247, não foram apreciados, receberam críticas de estarem muito relacionados às ideias estrangeiras, assim, a Reforma Leôncio de Carvalho vigorou até o início da República, e, no ano de 1890, foi aprovada a Reforma Benjamin Constant.

\section{Referências}

ALMEIDA, José Ricardo Pires de. História da instrução pública no Brasil (1500 a 1889). Tradução: Antonio Chizzotti. São Paulo: EDUC; Brasília, INEP/MEC, 1989.

AZEVEDO, Fernando de. A cultura brasileira. Brasília: UnB, 1963.

BARBOSA, Rui. Reforma do ensino secundário e superior. In: Obras completas. v. IX, tomo I. Rio de Janeiro: Ministério da Educação e Saúde, 1942.

Reforma do ensino primário e várias instituições complementares da instrução pública. In: Obras completas. v. X, tomo I ao IV. Rio de Janeiro: Ministério da Educação e Saúde, 1947.

Lições de coisas. In: Obras completas. v. XIII, tomo I. Rio de Janeiro: Ministério da Educação e Saúde, 1956.

CALVI, Lourdes Margareth. As transformações sociais e a instrução pública: uma análise dos projetos de reforma educacional e dos relatórios ministeriais de 1868 a 1879. Maringá: Universidade Estadual de Maringá, 2003. (Dissertação de Mestrado). 
CARVALHO, Carlos Leôncio de. Decreto 7.247 - Reforma do Ensino Primário e Secundário do Município da Corte e o Superior em todo o Império. In: BARBOSA, Rui. Reforma do Ensino Secundário e Superior. Obras Completas. v. IX, tomo I, Rio de Janeiro, Ministério da Educação e Saúde, 1942. p. 273-303.

CUNHA, Luiz Antônio. A universidade temporã. Rio de Janeiro: Francisco Alves, 1986.

HAIDAR, Maria de Lourdes Mariotto. O ensino secundário no império brasileiro. São Paulo: Grijalbo, 1972.

HOLANDA, Sérgio Buarque. História geral da civilização brasileira. São Paulo: Difel, 1985.

MACHADO, Maria Cristina Gomes. Rui Barbosa: Pensamento e ação. Campinas, SP: Autores Associados, 2002.

Fontes e história das instituições escolares: o projeto educacional de Rui

Barbosa no Brasil. In: LOMBARDI, José Claudinei; NASCIMENTO, Maria Isabel Moura (Orgs.). Fontes, história e historiografia da educação. Campinas, SP: Autores Associados; Curitiba: Pontifícia Universidade Católica do Paraná; Palmas: Centro Universitário Diocesano do Sudoeste do Paraná (UNICS); Ponta Grossa: Universidade Estadual de Ponta Grossa, 2004. p. 65-83.

O Decreto de Leôncio de Carvalho e os Pareceres de Rui Barbosa em Debate: A criação da escola para o povo no Brasil no século XIX. In: STEPHANOU, Maria; BASTOS; Maria Helena Camara (Orgs.). Histórias e memórias da educação no Brasil: Século XIX. Petrópolis, RJ: Vozes, 2005. p. 91-103.

Carlos Leôncio de Carvalho (Verbete). In: LOMBARDI, José Claudinei; SAVIANI, Dermeval; NASCIMENTO, Maria Isabel Moura. (Orgs.). Navegando pela história da educação brasileira. Campinas, SP: FE; HISTEDBR, 2006a. DR-Rom.

Referências documentais - Carlos Leôncio de Carvalho (Verbete). In:

LOMBARDI, José Claudinei; SAVIANI, Dermeval; NASCIMENTO, Maria Isabel Moura. (Orgs.). Navegando pela história da educação brasileira. Campinas, SP: FE; HISTEDBR, 2006 b. DR-Rom.

RIBEIRO, Maria Luisa Santos. História da educação brasileira: a organização escolar. Campinas, SP: Autores Associados, 1993.

SAVIANI, Dermeval. História das idéias pedagógicas no Brasil. Campinas, SP: Autores Associados, 2007.

SCHELBAUER, Analete Regina. O método intuitivo e lições de coisas no Brasil do século XIX. In: STEPHANOU, Maria; BASTOS; Maria Helena Camara (Orgs.). Histórias e memórias da educação no Brasil: Século XIX. Petrópolis, RJ: Vozes, 2005. p. 132- 149.

VALDEMARIN, Vera Tereza. O liberalismo demiurgo: estudo sobre a reforma educacional projetada nos pareceres de Rui Barbosa. São Paulo: Cultura Acadêmica, 2000. 


\begin{abstract}
${ }^{1}$ Em 1876, acentua-se no país a política imigratória com as entradas de 30567 imigrantes, desses, 1303 encaminharam-se para a província de São Paulo. Em 1881, houve a instalação, nessa província, dos serviços de imigração que subvencionou a entrada de imigrantes, após o ano de 1888, com a abolição da escravatura, percebe-se uma intensificação na vinda de imigrantes. Registros revelam a entrada de 133253 imigrantes, com a ida de 91826 para a província de São Paulo nessa época. (AZEVEDO, 1963).
\end{abstract}

${ }^{2}$ Transcrevemos uma biografia sintética de Carlos Leôncio de Carvalho: "Carlos Leôncio de Carvalho, [...] nasceu em 18 de junho de 1847, na cidade de Iguaçu, na província do Rio de Janeiro, era filho do Dr. Carlos Antonio de Carvalho. Estudou na Faculdade de Direito de São Paulo, tendo concluído seus estudos em 1868. Prestou concurso, em 1871, para professor nesta Faculdade e nele foi aprovado, sendo nomeado membro catedrático em 1881. Foi convidado para ocupar a pasta dos Negócios do Império no gabinete de 15 de janeiro de 1878, tendo sido eleito deputado pela província de São Paulo neste mesmo ano, permaneceu na Câmara até 1881. Leôncio de Carvalho, por meio do Decreto de 19 de abril de 1879, reformou a instrução pública primária e secundária no Município da Corte e o ensino superior em todo o Império, este deu origem aos Pareceres/Projetos de Rui Barbosa intitulados Reforma do Ensino Secundário e Superior (1882) e Reforma do Ensino Primário e várias Instituições Complementares da Instrução Pública (1883). Nesse Decreto autorizava o governo a criar ou auxiliar, nas províncias, cursos para o ensino primário, permitindo que os escravos freqüentassem as escolas. Buscava também estimular a alfabetização dos adultos, exigindo a leitura e escrita, dando preferência para obtenção de empregos nas oficinas do Estado aos indivíduos que cursaram a instrução primária. No Relatório de 1878, como Ministro, Leôncio de Carvalho chamara a atenção da Assembléia Legislativa para a importância da criação de cursos para o ensino primário destinado aos adultos devido a discussão, na Câmara dos Deputados, da reforma do sistema eleitoral que colocava como exigência que se soubesse ler e escrever para o exercício do voto. Instituiu a liberdade de ensino e a liberdade de frequiência, tais medidas causaram muita polêmica, recebendo críticas por facilitar o crescimento das escolas particulares e ser sua proposta "excessivamente" liberal. Participou da organização da exposição pedagógica, em 1883, em cujo congresso assumiu o cargo de secretário, bem como foi presidente da Associação Propagadora dos Cursos Noturnos. Sua reforma educacional marcou uma etapa importante na educação brasileira, mas provocou também uma acirrada oposição que o levou a se demitir da pasta. Como deputado por São Paulo, na tribuna da Câmara, defendeu das críticas, contudo ao terminar seu mandato, não conseguiu ser reeleito. Na República, durante alguns meses, assumiu o cargo de diretor da Faculdade de Direito de São Paulo. Exonerou-se por ter entrado em conflito com seus colegas de congregação, contrários à reforma da instrução pública feita pelo Governo Provisório, na qual colaborara. Foi senador estadual no governo de Américo Brasiliense. Jubilou-se, mudou-se para o Rio de Janeiro onde foi lente e diretor da Faculdade Livre de Direito. Faleceu a 9 de fevereiro de 1912" (MACHADO, 2006 a).

${ }^{3}$ Sobre o conjunto de obras de Carlos Leôncio de Carvalho destaca-se: "Teses e dissertação para obter o grau de doutor, São Paulo, 1869, 21 páginas. O ponto da dissertação é: "Nas ações executivas tem lugar a suspeição do juiz?"; Teses e dissertação para o concurso a uma cadeira vaga, São Paulo, 1870, 22 páginas. O ponto da dissertação é o seguinte: "Pode o cego fazer testamento, cerrando?"; Faculdade de Direito de São Paulo. Memória histórica do ano de 1874. Rio de Janeiro, 1875, apresentada no Relatório do Ministério dos Negócios do Império.; Reforma eleitoral. Naturalização dos estrangeiros. Rio de Janeiro, 1888 - É um opúsculo, em que o autor dá as razões que tivera para opor-se às emendas à nova lei de eleições, e que não pudera expor na câmara temporária. Alguns trechos desse opúsculo, onde se discutem também questões políticas e sociais, foram reproduzidas na Gazeta de Notícias, do Rio de Janeiro.; Educação da infância desamparada: conferência realizada durante a exposição pedagógica do Rio de Janeiro. Rio de Janeiro, 1883, 30 páginas. Publicado novamente no volume "Conferências efetuadas na exposição pedagógica" publicada no Rio de Janeiro, em 1884.; Primeira exposição pedagógica no Rio de Janeiro (documentos.) Rio de Janeiro, 1884. Em uma introdução de 259 páginas, Carvalho apresenta os acontecimentos da exposição e mostra, com o estudo das legislações e dos pareceres ali tratados, os princípios geralmente dotados na organização do ensino primário.;Atas e pareceres do congresso de instrução pública do Rio de Janeiro. Rio de Janeiro, 1884.; Relatório apresentado na $1^{\mathrm{a}}$ sessão da $17^{\mathrm{a}}$ legislatura pelo ministro e secretário dos negócios do império, Rio de Janeiro, 1878.; Relatório apresentado na $2^{\mathrm{a}}$ sessão da $17^{\mathrm{a}}$ legislatura, etc. em 1879. Rio de Janeiro, 1879.; Destaca-se que Carvalho enquanto estudante escreveu artigos para jornais: Palestra Acadêmica: Revista Científica e Literária. Publicação mensal sob a direcção de Candido Leitão, Didimo da Veiga e Leôncio de Carvalho. S. Paulo, 1866. O Acadêmico: jornal jurídico, literario e de notícias. Diretores da redação: Leôncio de Carvalho e J. F. Vianna. S. Paulo, 1868. Tribuna Liberal: jornal político e literário. São Paulo, 1867.; BRASIL. Decreto-Lei $n^{\circ} 7247$, de 19 de abril de 1879. Reforma do ensino primário, secundário e superior no município da Corte em todo o Império In: Relatório do ano de 1878, apresentado 
à Assembléia Geral Legislativa na $2^{\mathrm{a}}$ Sessão da $17^{\mathrm{a}}$ Legislatura. Rio de Janeiro: Typ. Nacional, 1879.; BRASIL. Ministério do Império. Ministro Carlos Leôncio de Carvalho Relatório do ano 1877 apresentado à Assembléia Geral Legislativa na $1^{\mathrm{a}}$ Sessão da $17^{\mathrm{a}}$ Legislatura. Rio de Janeiro: Typ. Nacional, 1878.; BRASIL. Ministro Carlos Leôncio de Carvalho. Relatório do ano de 1878, apresentado à Assembléia Geral Legislativa na $2^{\mathrm{a}}$ Sessão da $17^{\mathrm{a}}$ Legislatura. Rio de Janeiro: Typ. Nacional, 1879.; CARVALHO, Leôncio de (org). Documentos. Exposição Pedagógica do Rio de Janeiro, 1 (1883). Rio de Janeiro: Tipografia Nacional, 1884" (MACHADO, 2006b).

${ }^{4}$ Sobre os princípios das Lições de Coisas e Método Intuitivo, destacamos que o processo do ensinar é considerado a partir da aprendizagem do "simples para o complexo"; "do que se sabe para o que se ignora"; "dos fatos, para as causas"; "das coisas, para os nomes; das idéias, para as palavras; dos princípios, para as regras." (BARBOSA, 1956, p. 3), os sentidos são aqueles que possibilitam a apreensão da realidade e dos conhecimentos, nas palavras de Calkins, são os elementos que fornecem ao "espírito" "meios de comunicação" com o mundo exterior. O método considerava ser por intermédio das sensações, pela percepção, que o homem se apropriava do entendimento e conhecimento de mundo, sendo que a percepção levava às concepções (ideias), que a memória podia reter. (BARBOSA, 1956, p. 4) O princípio fundamental era a prática de se estudar os objetos, passando dos objetos às palavras, para o ensino dos símbolos representativos, ou os sinais, das coisas, assim, a aprendizagem ocorreria pela experiência por meio da intuição dos sentidos. 